\title{
Zn sorption on Ca-illite and Ca-smectite: experiment and modelling
}

\author{
Christelle Latrille ${ }^{1, *}$, Aubéry Wissocq ${ }^{1}$, and Catherine Beaucaire ${ }^{1}$ \\ ${ }^{1}$ Den-Service d'Etude du Comportement des Radionucléides (SECR), CEA, Université Paris-Saclay, \\ F-91191, Gif-sur-Yvette, France
}

\begin{abstract}
To predict $\mathrm{Zn}$ behaviour in soil, the retention properties of clay minerals plays a relevant role. In a continental environment, $\mathrm{Ca}$ is the main cation in solution. Soil reactivity may be reduced to sorption properties of $\mathrm{Zn}$ and $\mathrm{Ca}$ on illite and smectite, the major clay minerals in soil. With this assumption, a multi-site ion exchanger model has successfully been applied to the $\mathrm{Zn}$ sorption on Ca-illite and Ca-smectite. New batch experiments performed in this study enabled to collect sorption data for $\mathrm{Zn}$ on Ca-illite by concentration and $\mathrm{pH}$ isotherms. $\mathrm{Zn}$ sorption reversibility was then verified. These sorption data were modelled successfully with a multi-site ion exchanger (MSIE) formalism by using four sorption site types. $\mathrm{Zn}$ sorption isotherms on smectite were retrieved from literature and interpreted following the MSIE formalism. The obtained selectivity coefficients may be thereafter put into ion exchange models to describe the Zn sorption in natural environments.
\end{abstract}

\section{Introduction}

In the context of environmental monitoring of nuclear sites, or to evaluate the impact of metallurgic facilities, migration of $\mathrm{Zn}$ in soils, sediments and aquifers needs to be understood and well predicted. Migration of trace elements is partly governed by chemical sorption phenomena on mineral surfaces, especially on clay minerals known to have negatively surface charges compensated by cations [1]. Specific sorption sites are recognized for their high affinity for $\mathrm{Zn}$ on smectite and illite [2-3]. With this purpose, many sorption models consider sorption processes as ion exchange or surface complexation phenomena [1-5]. A multi-site ion exchanger model [4] using sorption property of pure smectite recently described with success the sorption of $\mathrm{Zn}$ on natural sediment under static conditions [5]. In this macroscopic approach, sorption sites are described by their sorption capacities (expressed in mol/ $\mathrm{kg}$ of solid phase) and their affinity towards chemical elements. Any chemical and mineralogical assignment of the sorption sites is impossible by this sole macroscopic and thermodynamic approach. Sorption experiment data result from $\mathrm{pH}$ and concentration isotherms, which support the mineral retention properties.

Among the most abundant minerals in natural soils and sediments, illite and smectite are recognized to play a determining role in cation adsorption. Many studies were dedicated

*Corresponding author: christelle.latrille@cea.fr 
to characterize illite and smectite retention properties, mainly performed on sodic media. On the contrary, despite the extensive presence of $\mathrm{Ca}$ in the natural environment, $\mathrm{Zn}$ sorption on illite has never been studied in presence of $\mathrm{Ca}$.

The purpose of this study was, (1) to assess the clay mineral exchange properties that drive the $\mathrm{Zn}$ uptake on those surfaces, (2) to evidence the affinity of $\mathrm{Zn}$ for these minerals and, (3) to discuss the relative role played by clay minerals in $\mathrm{Zn}$ adsorption by comparing their respective affinity towards $\mathrm{Zn}$. Filling the data gap on $\mathrm{Zn}$ sorption onto $\mathrm{Ca}$-illite, $\mathrm{pH}$ and concentration isotherms were acquired in batch experiments. Then, sorption and its reversibility were tested over a large $\mathrm{pH}$ range and $\mathrm{Zn}$ concentrations. A thermodynamic multi-site ion exchange model was used to interpret these new experimental data and those previously acquired on Ca-smectite [2] and Na-illite [3].

\section{Multisite ion exchange model}

The Multi-Site Ion Exchanger model is based on thermodynamics of chemical equilibria, and considers minerals as ion-exchangers described by negatively charged adsorption sites. For a complete description of the approach, readers can refer to [1-4, 5]. This theory is only based on a macroscopic description, and does not imply any structural hypothesis on minerals [4]. Thus, the exchange behaviour of each cation (here, $\mathrm{Ca}^{2+}$ and $\mathrm{Zn}^{2+}$ ) has to be studied individually as a function of $\mathrm{pH}$ and concentration on purified clay minerals. Then, $\mathrm{H}^{+}$is taken as reference cations.

Classically, cation exchange between $\mathrm{H}^{+}$and $\mathrm{M}^{\mathrm{m}+}$ for a given sites $\mathrm{X}_{\mathrm{i}}^{-}$is expressed by equation 1 .

$$
\mathrm{m}\left\{\left(\mathrm{X}_{\mathrm{i}}^{-}\right)-\mathrm{H}^{+}\right\}+\mathrm{M}^{\mathrm{m}+}=\left\{\left(\mathrm{X}_{\mathrm{i}}^{-}\right)_{\mathrm{m}}-\mathrm{M}^{\mathrm{m}+}\right\}+\mathrm{mH}^{+}
$$

Then, the equilibrium constant of this reaction is written as follow in equation 2 :

$$
\begin{aligned}
\mathrm{K}_{\mathrm{M}^{\mathrm{m}+} / \mathrm{H}^{+}}^{\mathrm{i}} & =\frac{\left(\mathrm{X}_{\mathrm{i}}^{-}-\mathrm{H}^{+}\right)^{\mathrm{m}}\left(\mathrm{M}^{\mathrm{m}+}\right)}{\left(\left(\mathrm{x}_{\mathrm{i}}^{-}\right)_{\mathrm{m}} \mathrm{M}^{\mathrm{m}+}\right)\left(\mathrm{H}^{+}\right)^{\mathrm{m}}} \\
\mathrm{K}_{\mathrm{M}^{\mathrm{m}+} / \mathrm{H}^{+}}^{\mathrm{i} *} & =\frac{\left[\mathrm{X}_{\mathrm{i}}^{-}-\mathrm{H}^{+}\right]^{\mathrm{m}}\left[\mathrm{M}^{\mathrm{m}+}\right] \gamma_{\mathrm{M}} \mathrm{m+}}{\left[\left(\mathrm{X}_{\mathrm{i}}^{-}\right)_{\mathrm{m}} \mathrm{M}^{\mathrm{m}+}\right]\left[\mathrm{H}^{+}\right]^{\mathrm{m}} \gamma_{\mathrm{H}^{+}}^{\mathrm{m}}}
\end{aligned}
$$

where $\mathrm{K}^{\mathrm{i}}$ is the selectivity coefficient, $i$ is the type of sorption site. () and [] represent activities and concentrations of species, respectively. Species in solution are in mol. $\mathrm{L}^{-1}$ whereas adsorbed species are in mol. $\mathrm{kg}^{-1}$ (of dry clay mineral). $f$ (in $\mathrm{kg} \cdot \mathrm{mol}^{-1}$ ) is the activity coefficient of each adsorbed species and $\gamma$ (in L. $\mathrm{mol}^{-1}$ ) is the activity coefficient of the species in solution. All $f^{\prime}$ are unknown and are included in the corrected selectivity coefficient $\mathrm{K}_{\mathrm{M}^{\mathrm{m}+} / \mathrm{H}^{+}}^{\mathrm{i}}$.

For cations such as $\mathrm{Zn}$, the complexation in solution by $\mathrm{OH}^{-}$must be taken into account. Consequently, $\mathrm{Zn}(\mathrm{OH})_{2}$ complex has been considered to calculate $\mathrm{Zn}^{2+}$ concentration at $\mathrm{pH}>8$, given that $\left[\mathrm{Zn}^{2+}\right]=[\mathrm{Zn}(\mathrm{II})] / \alpha_{\mathrm{Zn}}$ with $\alpha_{\mathrm{Zn}}=1.23$.

In this study, $\mathrm{Zn}$ sorption isotherms are acquired on purified illite and $\mathrm{Zn}$ sorption data acquired on Ca-smectite were retrieved from [4]. Selectivity coefficients between $\mathrm{Ca}^{2+}$ and $\mathrm{Zn}^{2+}$ can be determined using the ratio of both $\mathrm{K}_{\mathrm{Ca} 2+/ 2 \mathrm{H}+}^{\mathrm{i}}$ and $\mathrm{K}_{\mathrm{Zn} 2+/ 2 \mathrm{H}+}$ selectivity coefficients. 


\section{Materials and experimental methods}

\subsection{Clay conditioning}

In order to study $\mathrm{Zn}^{2+}$ exchange by only $\mathrm{Ca}^{2+}$ on clay sorption sites, illite was conditioned under homo-ionic Ca-form. Thus, illiteSA14(from Les Salins, France, close to le Puy en Velay) was initially purified by dissolving carbonate in $0.1 \mathrm{M} \mathrm{HCl}$ solution and by sieving at $50 \mu \mathrm{m}$. Clay was dispersed in $1 \mathrm{M} \mathrm{CaCl}_{2}$ with a $1: 10$ solid/solution ratio, shaken for $24 \mathrm{~h}$ on an orbital shaker and centrifuged to replace the supernatant by a $1 \mathrm{M} \mathrm{CaCl}_{2}$ solution. The operation was repeated 5 times. Two similar operations were successively realized with $0.1 \mathrm{M} \mathrm{CaCl}_{2}$ and ethanol to eliminate residual salt. After centrifugation, conditioned clay material was left to air-dry for 2 days.

\subsection{Sorption isotherm experiments}

Two $\mathrm{Zn}$ sorption isotherms ( $\mathrm{pH}$ dependent isotherm and concentration isotherm) were acquired on Ca-illite. Batch sets with 28centrifugation tubes were prepared by dispersing $0.11 \mathrm{~g}$ of Ca-conditioned illite in $5 \mathrm{ml}$ of $0.01 \mathrm{M} \mathrm{CaCl}_{2}$ solution. In the case of $\mathrm{pH}$ isotherm, $\mathrm{pH}$ was adjusted for each tube to cover a range from 2 to 12 using $\mathrm{HNO}_{3}{ }^{-}$or $\mathrm{Ca}(\mathrm{OH})_{2}$ solutions and tubes were shaken for a few hours. In case of concentration isotherm, $50 \mu \mathrm{L}$ of $\mathrm{ZnCl}_{2}$ stable solution ranged between $2 \mathrm{M}$ to $2.10^{-7} \mathrm{M}$ was added and $\mathrm{pH}$ was maintained to 6.5. Subsequently suspensions were spiked with ${ }^{65} \mathrm{Zn}$ by adding $70 \mu \mathrm{l}$ of a solution $\mathrm{ZnCl}_{2}$ dissolved in $0.1 \mathrm{M} \mathrm{HCl}$, in order to introduce $9500 \mathrm{~Bq}$ in each tube. Then batches were shaken for 6 days. After centrifugation, the activity of $1 \mathrm{ml}$ aliquot of supernatant of each tube was measured by gamma counting and the total concentration in solution at equilibrium was measured by ion chromatography.

The concentration of adsorbed $\mathrm{Zn}$ is given by:

$$
\mathrm{K}_{\mathrm{d}}=\frac{\overline{[\mathrm{M}]}}{[\mathrm{M}]}=\left(\frac{\mathrm{A}_{0}}{\mathrm{~A}}-1\right) \frac{\mathrm{V}}{\mathrm{m}}
$$

where $\mathrm{Kd}$ is the solid-solution distribution coefficient, $[\overline{\mathrm{M}}]$ and $[\mathrm{M}]$ are respectively total concentration at equilibrium of adsorbed $\mathrm{M}$ and total concentration in solution of $\mathrm{M}, \mathrm{A}_{0}$ is the initial solution activity, A the activity at equilibrium in solution, $\mathrm{m}$ the total dry mass of solid and $\mathrm{V}$ the total volume of solution.

$\mathrm{Zn}$ sorption reversibility was investigated on Ca-illite. Reversibility is achieved when desorption $\mathrm{Kd}$ is equivalent to the adsorption $\mathrm{Kd}$. In this case, $\mathrm{H}^{+}$and $\mathrm{Ca}^{2+}$ concentrations as well as the solid/solution ratio are maintained the same in sorption and desorption experiments.

\section{Results and discussion}

For illite and smectite adsorption is $\mathrm{pH}$ dependent. In case of illite, $\operatorname{LogKd}$ increase from 3 to 5 between $\mathrm{pH} 2.5$ to $\mathrm{pH} 8$ (Fig. 1) until it reaches a plateau with roughly constant logKd. This highlights the competition with protons and the progressive exchange with $\mathrm{Zn}$ on sorption sites, as the electrolyte $\mathrm{Ca}$ remain at constant concentration in the system. In figure 2, partitioning coefficients are expressed in function of $\mathrm{Zn}$ concentrations measured at sorption equilibrium in the supernatant at fixed $\mathrm{pH}$. LogKd values for comparable $\mathrm{pH}$ and $\mathrm{Zn}$ concentrations are similar to those from $\mathrm{pH}$ isotherms in both experiments. $\mathrm{Zn}$ sorption reversibility is verified on Ca-illite. Illite and smectite have to be described as cation exchangers with four sites. Although, smectite expresses a larger cation exchange capacity 
than illite (table 1), the estimated minor sites capacities (Xs and X0) are close for both clay minerals, reaching 2.7 meq. $\mathrm{kg}^{-1}$ and 1.6 meq. $\mathrm{kg}^{-1}$, respectively (table 1 ). They were estimated at 2 meq. $\mathrm{kg}^{-1}$ on a Ca-smectite [2] and on Na-illite [3] to model $\mathrm{Zn}$ sorption. The four sites considered in the model allow correct fitting of the illite experimental data (fig. 1 and 2). Individual site contributions show that the high reactive sites ( $\mathrm{X} 0$ and $\mathrm{X} 3$ ) are dominant at $\mathrm{pH}$ below 4 (X0) and up to 7 (X3) in the $\mathrm{Zn}$ uptake. Between $\mathrm{pH} 4$ to 7, the $\mathrm{X} 2$ site contributes whereas the major site $\mathrm{X} 1$ appears with a neglecting effect.

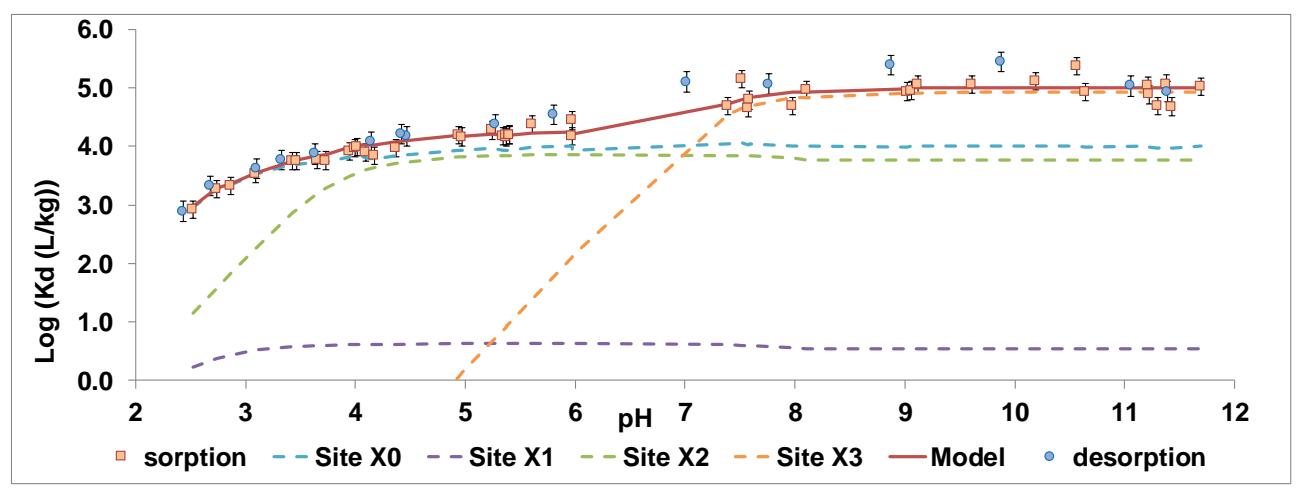

Fig. 1. Logarithm of the $\mathrm{Zn}$ distribution coefficient vs. $\mathrm{pH}$ at equilibrium on Ca-illite $(\mathrm{I}=0.03 \mathrm{M})$ with introduced $\mathrm{Zn}$ concentration at $8.710^{-6} \mathrm{M}$ and the modelling outcome (redline). Contribution of the high-capacity site X1 (violet dashed line) and the low-capacity site X0 (blue dashed line), the minor site X2 and X3 (resp. orange and green dashed lines).

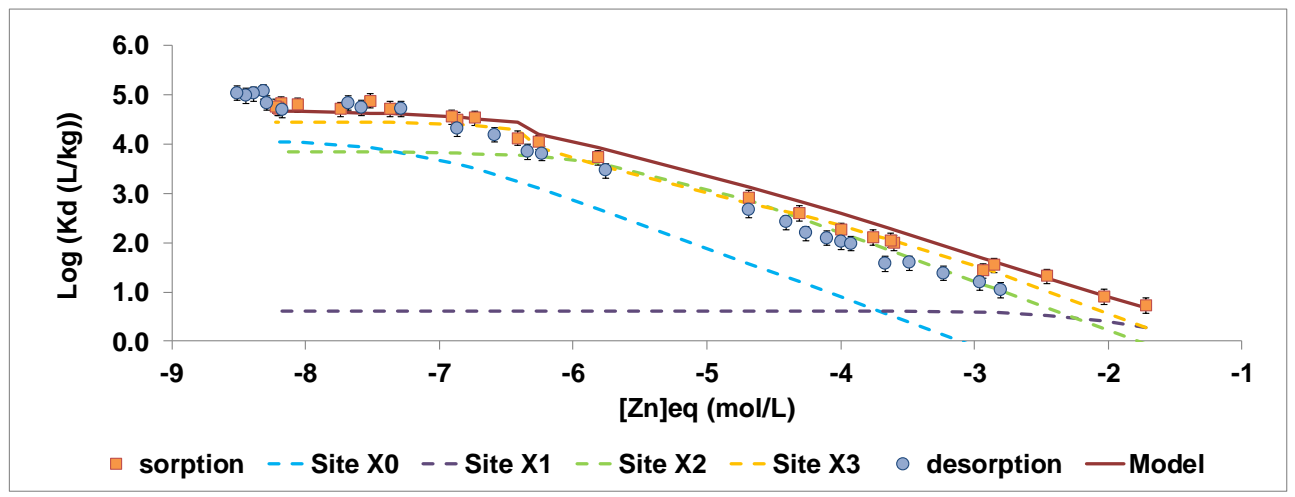

Fig. 2. Logarithm of the $\mathrm{Zn}$ distribution coefficient vs. the $\mathrm{Cs}$ concentration at equilibrium $(\mathrm{pH}=7.3)$ on Ca-illite $(\mathrm{I}=0.03 \mathrm{M})$ and the modelling outcome (redline). Contribution of the high-capacity site X1 (violet dashed line) and the low-capacity site X0 (blue dashed line), the minor site X2 and X3 (resp. orange and green dashed lines). 


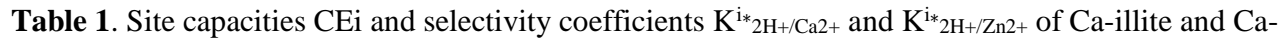
smectite [2] determined and used in this study. The uncertainties given correspond to $1 \sigma$. . $\mathrm{A}$ " marks data issued from [1].

\begin{tabular}{|c|c|c|c|c|}
\hline Mineral & Sites & $\begin{array}{c}\mathrm{CEi}_{\mathrm{i}} \\
\left(\mathrm{eq} \cdot \mathrm{kg}^{-1}\right)\end{array}$ & $\mathrm{K}^{\mathrm{i}_{*}} \mathrm{H}^{+} / \mathrm{Ca}^{2+A}$ & $\mathrm{~K}^{\mathrm{i}^{*}} 2 \mathrm{H}^{+} / \mathrm{Zn}^{2+}$ \\
\hline \multirow{4}{*}{ Illite } & $\mathrm{X}_{0}$ & $1.6 .10^{-3}$ & $-0.40 \pm 1.98$ & $4.82 \pm 0.75$ \\
\cline { 2 - 5 } & $\mathrm{X}_{1}$ & $0.13^{A}$ & $-2.17 \pm 0.07$ & $-2.35 \pm 2.23$ \\
\cline { 2 - 5 } & $\mathrm{X}_{2}$ & $0.04^{A}$ & $-4.31 \pm 0.272$ & $-0.66 \pm 0.61$ \\
\cline { 2 - 5 } & $\mathrm{X}_{3}$ & $0.07^{A}$ & $-11.75 \pm 0.21$ & $-7.28 \pm 0.12$ \\
\hline \multirow{5}{*}{ Smectite } & $\mathrm{X}_{\mathrm{s}}$ & $2.7 .10^{-3}$ & $-0.22 \pm 0.18$ & $-2.22 \pm 0.10$ \\
\cline { 2 - 5 } & $\mathrm{X}_{\mathrm{a}}$ & $0.39^{A}$ & $-0.49 \pm 0.49$ & $-0.42 \pm 0.37$ \\
\cline { 2 - 5 } & $\mathrm{X}_{\mathrm{b}}$ & $0.36^{A}$ & $-4.35 \pm 0.03$ & $-4.08 \pm 2.38$ \\
\cline { 2 - 5 } & $\mathrm{X}_{\mathrm{c}}$ & $0.14^{A}$ & $-14.84 \pm 0.06$ & $-9.44 \pm 0.45$ \\
\hline
\end{tabular}

Even that available data on $\mathrm{Zn}$ sorption were acquired at different ionic strength, sorption trends due to ionic competition and mineral dependence may be evidenced. Compared to $\mathrm{pH}$ sorption isotherm acquired on Na-illite [3], $\mathrm{Zn}$ sorption on Ca-illite is lower (Fig. 3) whatever the $\mathrm{pH}$ value. This expresses a larger competition between $\mathrm{Zn}$ and $\mathrm{Ca}$ compared to $\mathrm{Na}$ as previously observed on Cs sorption on smectite [6]. Considering the ionic strength difference, Ca-illite adsorbs more $\mathrm{Zn}$ than Ca-smectite [2] at $\mathrm{pH}<7$ and inversely at $\mathrm{pH}>7$. This confirms a larger $\mathrm{X} 0$ affinity than the one of Xs.

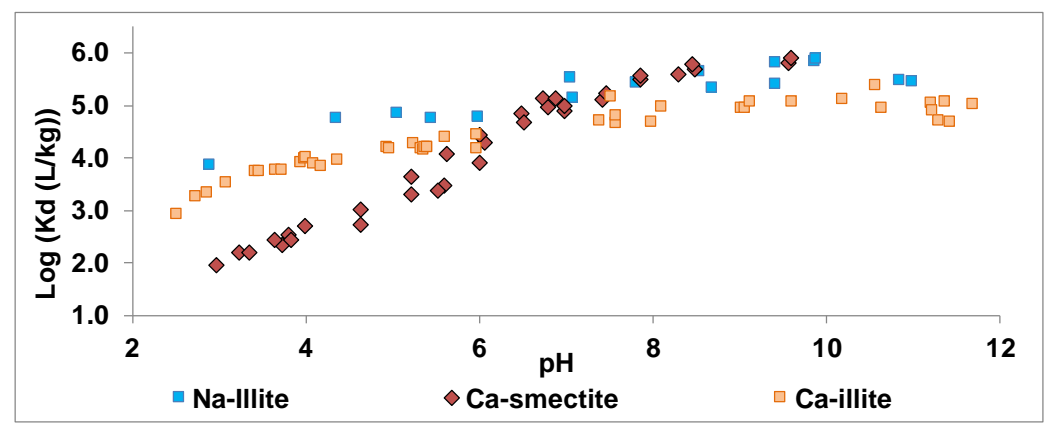

Fig. 3. Logarithm of the $\mathrm{Zn}$ distribution coefficient vs. $\mathrm{pH}$ at equilibrium on Ca-illite ( $\mathrm{I}=0.03 \mathrm{M}$, this study), on Ca-smectite $\left(\left[\mathrm{Ca}\left(\mathrm{NO}_{3}\right)_{2}\right]=3.310^{-3} \mathrm{M}[4]\right)$ and on $\mathrm{Na}$-illite $\left(\left[\mathrm{NaClO}_{4}\right]=0.1 \mathrm{M}\right.$, [5]).

\section{References}

1. A.Wissocq, C. Beaucaire, C. Latrille, Appl. Geochem. 93, 167 (2018)

2. M. Bradbury, B.Baeyens, Geochim. et Cosmochim. Acta, 63, 325 (1999)

3. S. Altmann, M. Aertsens, T. Appelo, C. Bruggeman, S. Gaboreau, M. Glaus, P. Jacquier, T. Kupcik, N. Maes, V. Montoya, T. Rabung, J.-C. Robinet, S. Savoye, T. Schaefer, C. Tournassat, L. Van Laer, L. Van Loon, CatClay Final Scientific Report D1.6. (2014)

4. Motellier, S., Ly, J., Gorgeon, L., Charles, Y., Hainos, D., Meier, P., Page, J., Appl. Geochem. 18, 1517 (2003)

5. E. Tertre, C. Beaucaire, N. Coreau, A. Juery, Appl. Geochem. 24, 1852 (2009)

6. T. Missana, A. Benedicto, M. Garcia-Gutierrez, U. Alonso, Geochim. et Cosmochim. Acta, 128, 266 (2014) 